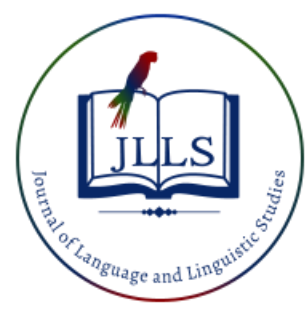

Available online at www.jlls.org

JOURNAL OF LANGUAGE AND LINGUISTIC STUDIES

ISSN: 1305-578X

Journal of Language and Linguistic Studies, 16(3), 1621-1636; 2020

\title{
Unpacking the challenges and accommodation strategies of Omani English-Major students on IELTS academic reading tests
}

\author{
Holi Ibrahim Holi Ali a 1 iD, Qasim Al Washahib iD, Awad Alhassan ${ }^{c}$ iD \\ ${ }^{a}$ University of Technology and Applied Sciences, Rustaq, Sultanate of Oman \\ ${ }^{\text {the }}{ }^{a}$ University of Technology and Applied Sciences, Rustaq, Sultanate of Oman \\ APA Citation: \\ ${ }^{c}$ Dhofar University, Salalah, Sultanate of Oman \\ Holi, A. I., AlWashahi, Q., \& Alhassan, A. (2020). Unpacking the Challenges and Accommodation Strategies \\ of Omani English-Major Students on IELTS Academic Reading Tests. Journal of Language and Linguistic Studies, 16(3), $1621-1636$. \\ Submission Date:20/07/2020 \\ Acceptance Date:12/09/2020
}

\begin{abstract}
IELTS is used as a screening gatekeeper and plays a crucial role in Omani students to meet job requirements. This paper reports on Omani English-major undergraduate students' reflections on their experience of the reading section of Academic IELTS. The main aim of the study was to elucidate their difficulties and coping strategies to inform EFL/ESL teachers and IELTS examiners and researchers. An IELTS mock reading test, under exam conditions, was administered to 45 Omani students majoring in English, and the participants were asked to write a reflective essay in response to the following prompts: "What were the difficulties that you encountered in your IELTS Academic Reading test, and how did you handle those challenges?" Their answers touched upon their experience and challenges with the test (e.g. difficulties pertaining to cognition, content area knowledge, and the lack of familiarity with the test reading genres) as well as their strategies to address the challenges. The data were coded and analysed thematically and inductively. The findings showed that students reported a range of cognitive and metacognitive challenges and numerous coping strategies. This paper unravels some of the pedagogical implications and ideas that surfaced through the analysis of the students' responses.
\end{abstract}

(C) 2020 JLLS and the Authors - Published by JLLS.

Keywords: accommodation strategies; challenges; experiences; English-major Omani students; IELTS Academic Reading tests

\section{Introduction}

The English language has become a crucial tool not only for studying abroad but also for surviving in an English-speaking foreign work or academic environment (Feng \& Chen, 2016). English is highly valued by the Omani government and is considered a tool for modernisation and nationalisation (AlIssa, 2020). Consequently, the International English Language Testing System (IELTS) has become a benchmark for language proficiency, and "a key transnational achievement arena" (Templer, 2004, p. 191). Therefore, a decision was made by the Omani Ministry of Education to set Band 6 on the academic IELTS test as an official standard for hiring English language teachers (Al-Issa, Al-Bulushi, \& AlZadjali, 2016). However, a considerable number of graduates from English Language Teaching

\footnotetext{
${ }^{1}$ Holi Ibrahim . Tel.: + (+968) 26774818

E-mail address: Holi.ibrahim.rus@cas.edu.om
} 
programmes in Oman, such as those at Sultan Qaboos University (SQU) and Rustaq College of Education (RCoE), have encountered many challenges, particularly in reading, and notably struggled to achieve Band 6 in the IELTS; and this situation does not seem to be peculiar to Oman (Çiftlikli, 2018).

Reading is an important literacy skill that the learner needs to acquire to recreate the meaning shared through texts (Wahyono, 2019). This skill plays a key role in English language proficiency tests like IELTS and the Test of English as a Foreign Language (TOEFL), including TOEFL iBT, which have become increasingly popular tools to judge people's linguistic performance and critical thinking skills. Indeed, they have become the gatekeepers that decide people's merits to gain access to degree programmes and employment as well as their success in universities and colleges around the globe (Li, 2018; Schoepp \& Garinger, 2016; Uysal, 2009). Due to its immense popularity, IELTS is unique among other tests in terms of its claims to assess "English as an international language", indicating a recognition of the expanding status of English (Uysal, 2009). As a result, IELTS has become increasingly globalised, and the number of people taking it has continued to grow in recent years, standing at approximately three million test-takers in 2016 (Pearson, 2019). IELTS is available in two test versions: IELTS Academic and IELTS General Training, and is jointly owned, managed, and administered internationally by three associations, namely the British Council, Cambridge Assessment English, and the International Development Programme (IDP) of Australian Universities.

Since 1989, IELTS has been an appropriate language requirement for entry to professional courses and further/higher education in the UK, Australia and New Zealand (Charge \& Taylor, 1997), especially IELTS Academic (Hashemi \& Daneshfar, 2018). For example, in the UK, it is the most widely recognised test of English for academic purposes (Green, 2007). The test is currently being administered at approximately 1,100 venues in 140 countries at a rate of up to four times a month, and it is recognised by over 10,000 organisations globally (Pearson, 2019).

In Oman and elsewhere, IELTS is a criterion-referenced test that adequately predicts the test-takers' language proficiency levels. It is used to inform the decisions of higher education institutions (HEIs) and is also used by employers to assess prospective employees' ability to function in a workplace. It also plays a significant role in the language-proficiency-selection process for English-medium programmes for international Higher Education Institutions (Green, 2019; Pearson, 2019). However, the vast majority of non-native English-speakers (NNES) encounter several challenges in this test, particularly in the reading section, which is time-bound. IELTS is a 'high stakes' exam which often takes place at the end of an intensive course, with students under severe pressure to succeed (Issitt, 2008). Even newly qualified Omani English teachers have problems reaching band 6, even though they were presumed to have reached band $4.5 / 5.0$ by the start of their undergraduate English major programme and that they will have taken more than thirty English-focused courses (language awareness and use, linguistics, and literature) by the end of their bachelor's degree programme.

Both the Academic and General Training versions of the IELTS test provide a valid and accurate assessment of the four language skills (listening, reading, writing, and speaking). Both versions are scored in the same way. The applicants take the first three parts of the test during one session (first listening, then reading, and finally writing) with no breaks in between (Hashemi \& Daneshfar, 2018).

\subsection{Context and participants}

English in Oman is widely used in education, the health care system, and business. The prominence of English is because the most educated private sector is still largely dominated by a nonOmani and non-Arabic-speaking labour force. English in Oman is also important for tourism, which has flourished since the beginning of the current millennium (Al-Issa, 2020). 
At the same time, it must be added that other segments of the private sector that are populated mostly by Indian, Pakistani, and Bangladeshi labourers, farmers, mechanics, builders, plumbers and electricians, tea and coffee shop workers, barbers, laundry staff, and maids communicate predominantly in pidgin Omani Arabic and are practically unaffected by English.

This study was conducted in the education sector, where English still has a central position. More specifically, both the researchers and the participants were from the Department of English Language and Literature (ELL Dept) at Rustaq College of Education (RCoE), which, together with the Colleges of Applied Sciences (CAS), makes up the network of public colleges under the Ministry of Higher Education (MoHE), Oman.

RCoE offers three main streams: the English-medium B.Ed. in the English Language and a series of Arabic-medium bachelor's programs in the Sciences. The ELL Dept, in turn, runs three English-medium programs: English courses for students from the Arabic-medium degree programs (known as TPEN), the General Foundation Programme (or GFP, which is exclusively for the English-major students), and the B.Ed in the English Language. The foundation programme is streamed into four levels (A, B, C, and D), into which the newly admitted students are placed in the light of their performance in the placement test.

The B.Ed. is a four-year programme worth 132 credit hours designed to qualify graduates who are competent English users and ready to teach English in schools and the educational sector. The B.Ed. the programme comprises courses in language awareness and use, linguistics (both theoretical and applied), literature, education, and research. Upon graduation, the Ministry of Education only hires English teachers for cycle 1, cycle 2, and post-basic education who have scored band 6 on Academic IELTS and have passed a content exam based on educational and pedagogical matters.

\subsection{The nature of academic IELTS reading texts}

Reading comprehension is at the heart of the IELTS reading test. In this test, test-takers are required to read three passages consisting of 1500-2500 words. In this section, 38-42 questions should be answered in 60 minutes, and the difficulty level of texts and tasks increases throughout the paper. However, all topics are in a style appropriate to candidates entering undergraduate and postgraduate courses (IELTS Handbook, 2007).

The three types of reading passages in the IELTS Academic Reading test are narrative, descriptive, and argumentative, which are usually taken from books, magazines, or newspapers. The types of questions which appear in both Academic and General Training IELTS reading tests are multiple-choice questions (MCQs), true/false/not given, yes/no/not given, matching information, classifying information, matching headings, sentence/summary/note/chart completion, matching sentence endings, diagram label completion and short answer (Lougheed, 2016). However, the literature on the IELTS shows that the IELTS requires different and special language-learning strategies (LLS), which poses more challenges to the test-takers (see e.g., Chowdhury, 2009; Ying, 2011).

The Academic IELTS reading test includes three different passages and 40 questions in total and is mainly designed to test a wide range of reading skills. These include reading for gist, reading for main ideas, reading for details, skimming, understanding the logical argument, and recognising writers' opinions, attitudes, and purpose. Every passage is assigned 20 minutes and two of the passages have 13 following questions and one of the three has 14 questions. The IELTS Academic Reading test includes two main operations, namely, expedition reading operations and careful reading operations. The expedition operations consist of skimming and scanning, whereas careful operations demand higherorder thinking skills, and they include distinguishing facts from opinions and recognising an author's attitudes, understanding inferred information and inferring the meaning of unknown words from 
contexts (Alshammari, 2016). Careful reading is based on a process of slow, linear, incremental reading for comprehension. It seeks to extract complete meanings from a text and can occur at a local (i.e., sentence or clause) or global (i.e., paragraph or text) level, from within or beyond the sentence up to a whole text or series of texts. By contrast, expedition reading is quick, selective, non-linear, efficient, and primarily driven by time pressure (Chalmers \& Walkinsha, 2014). Therefore, critical reading strategies are of utmost importance for answering IELTS reading questions successfully.

Therefore, there are several attributes in IELTS Academic Reading which learners need to master, such as lexico-grammatical knowledge, making inferences, scanning for specific information, skimming for general information, connecting and synthesising information, and summarising (Mirzaei, Vincheh, \& Hashemian, 2020).

\subsection{IELTS Academic Reading: Challenges and reading strategies}

Reading as a key literacy skill is considered to be one of the most important skills for language learners, particularly EFL learners. Reading involves bottom-up and top-down processing skills; it depends on the integration of several cognitive and non-cognitive processes (Kendeou, Krista, \& Fulton, 2011). Reading skills are considered one of the most important skills to be mastered efficiently for succeeding in the academic field (Çiftlikli, 2018). Reading is viewed as a more dynamic process. The command of effective English reading strategies and skills is an essential concern for Omani graduates as their future in employment and academia depends on reading and writing skills (Alghail \& Mahfood, 2016). Reading comprehension is considered to be an activity of reconstructing a reasonable message from a written message which the person can understand and critically interpret and analyse (Feng \& Chen, 2016). Reading comprehension is, hence, a highly complex cognitive and mental process which demands the reader to draw a link between the text and its world, on the one hand, and the reader's schemata and recognition skills, on the other (Meneghetti, Carretti, \& De Beni, 2006). Indeed, reading comprehension requires cultural and metacognitive awareness, knowledge of grammar, syntactic knowledge, reading strategies, background knowledge, vocabulary knowledge, ability to recognise words and phrases, and synchronise text information rapidly and efficiently, understanding of the text type and genre, and other ranges of strategic and cognitive skills (see e.g., Grabe, 2009; Koda, 2007). Cognitive skills are the most important in reading comprehension (Wahyono, 2019), and IELTS reading is supposed to assess the candidate's skills for following instructions, finding the main ideas and the relationships between them, identifying the underlying concept(s), and drawing logical inferences. According to Alderson (2000), "IELTS' strength is in using multiple methods of text understanding of any passage, as in real life readers typically respond to reading texts in many ways" (p. 206).

Reading comprehension has four major levels a reader can experience when reading. They are ordered from the lowest to the highest: literal comprehension, interpretive or inferential comprehension, critical comprehension, and creative comprehension. Literal comprehension refers to the reader's understanding of what is explicitly stated in the text. Interpretive or inferential comprehension focuses on the reader's understanding of what is implicitly stated in the text utilising his/her schematic knowledge to grasp the meaning between the lines. Critical comprehension deals with the use of personal judgements after reading using higher-order critical thinking skills. Creative comprehension centres on the reader's engagement and emotional response towards what is being read (Feng \& Chen, 2016).

Effective reading comprehension is associated with critical reading skills and the appropriate strategy choice (Marzban \& Barati, 2016). However, effective readers face challenges as they read since they keep reading to get the most out of what they read (Guntur \& Pordanjani, 2019). An insufficient 
educational background was also reported as one of the difficulties that affect students' reading comprehension negatively (Alghail \& Mahfoodh, 2016).

Four strategies are used by readers namely: cognitive strategies, metacognitive strategies, compensation strategies, and effective strategies. Cognitive reading strategies include highlighting and underlining, transaction, pausing and thinking, skimming, predicting, paraphrasing, note-taking, reasoning deductively, re-reading, etc. Metacognitive strategies include self-monitoring, planning, selfquestioning, self-evaluation, and paying attention. Compensation strategies consist of using linguistic and non-linguistic clues to comprehend the text. Affective strategies include lowering anxiety for reducing the mental load of the reading task (Ahmadian, Poulaki \& Farahani, 2016).

Academic reading difficulties have been discussed in the literature, such as working out the meaning of difficult words, reading quickly to get the overall meaning, reading quickly to find information, understand specialist vocabulary, understanding organisation of a text, identifying key ideas, reading carefully to understand a text, identifying ideas/examples and time management (see e.g., Alghail \& Mahfood, 2016). For Academic IELTS reading test-takers, the time constraints are a major concern (Chalmers \& Walkinshaw, 2014). Moreover, the cultural differences between the IELTS test-writer and the test-taker are one of the major problems encountered by IELTS test-takers. Additionally, appropriate time management and lack of proper practice before the exam have also been reported as salient difficulties in the Academic IELTS reading test (Chowdhury, 2009). Further, Nuttal (1989) points out that students often have difficulties with the conceptual content of texts, particularly when the topic is unfamiliar to them or the reader and the writer are from different cultures, which is considered a cultural gap as they do not share the same assumptions (Chowdhury, 2009).

Time management during IELTS tests has been the most common problem that test-takers experience and the reason why they often cannot attend to all the questions. Effective time management is almost impossible, even for students with higher proficiency levels. Students frequently get caught up in solving the problems that they encounter along with the exam and, thus, fail to move forward on to the questions that they could easily answer. Such an infelicitous strategy often causes them to lose track of time (Chowdhury, 2009). However, test-takers are not expected to read every word in the text as the questions are designed to test their ability to process text quickly and to elicit specific information in a specific time (Hughes, 2003).

Findings from the literature show that international students use several accommodation strategies to handle the Academic IELTS reading test, including matching words that are both in the questions and the reading passages, reading key parts of the text (e.g. the introduction and conclusion, etc.), working out the meaning of a difficult word, reading the text or parts of it slowly and carefully, reading relevant parts of the text again, connecting information from the text with the knowledge that they already have, guessing the answer, and looking for parts of the text that, they think, the writer has highlighted or signposted as important (see e.g., Chalmers \& Walkinshaw, 2014).

Having reviewed the literature and to achieve its goal, the current study addressed the following two research questions: "What were the difficulties which test-takers encountered in your IELTS academic reading test, and how did test-takers handle them?

\section{Method}

The findings obtained from the sample of this study may not be generalisable to the whole population but provide an account relevant to other contexts beyond the study. 
The target population of the study included 45 Omani higher education students from the B.Ed in the English Language teaching (ELT) at an Education department in one of the Omani colleges of applied sciences. The study adopted a qualitative methodology by using the participants' written reflections on their experience with the Academic IELTS mock reading test that was administered to them under exam conditions. An IELTS mock reading test was administered and they were subsequently asked to write reflective essays on their experience with the test, ranging from cognitive problems to content area knowledge challenges, and familiarity with the reading genre. The reflective essays were taken up within an assessment course (PSYC 250 Assessment) that is offered in the third year and introduces students to the key concepts in language assessment and is assessed through a midterm exam (30\%), a project (20\%), and a final exam (50\%). Since the IELTS focuses considerably on demonstrating high-order thinking skills and strategies in listening, reading, speaking, writing and vocabulary using a wide range of materials, and task and text types and forms (Al-Issa, Al-Bulushi, \& Al-Zadjali), the mock test seemed to have been demanding for the participants.

The mock IELTS test was administered twice and framed within a course in assessment, more specifically an assessment project that was made up of two parts: part one focused on school-based assessment and part two was centred on standardised testing (the Academic IELTS reading test). Part two included the following prompts:

"This part should include your reflection of (500 words) on the IELTS reading test that you had in class. Here are some questions you can ask yourself: Describe your experience with the IELTS reading test - what were the challenges encountered in the reading test? How did you handle those challenges? What would you do differently in the future if you were asked to write an IELTS reading test?"

The two reading tests were administered to two groups of students during the academic year 20192020. The first reading test consisted of three passages which were taken from the "Cambridge English IELTS" and included authentic examination papers from Cambridge ESOL, considered an official "Cambridge Preparation Material for IELTS" (2011, pp. 18-22). The first reading passage was titled "A Chronicle of Timekeeping"; the second, "Air Traffic Control in the USA"; and the third, "Telepathy" (Cambridge English IELTS, 2011, pp. 18-29). The second reading test was adopted from "Barron's IELTS: The Leader in Test Preparation" (2016, pp. 301-323-Model Test 1). The data from the reflective essays were coded thematically and inductively. The mains themes were generated and around which further analysis of the data was conducted by establishing more analytical linkages both comparatively and contrastively among these themes (Miles \& Huberman, 1994). The study has some limitations such as the sample size and the scope which predominately focuses on students' reflections and experiences only in an academic reading component of the test.

\section{Findings}

This section weaves the story of English-major Omani students' experiences with an Academic IELTS reading test told in their own words and based on their reflections and perspectives about the Academic IELTS test's reading component. The findings are organised in a way that addresses the research questions which are based on the students' reflections to make the account more vivid and richer. The narrative includes the challenges encountered and the adaptation strategies used by the participants. 


\subsection{The challenges}

The participants encountered a series of challenges during the mock IELTS tests. For example, one of the students described his experience as both difficult and useful:

"I have gone through an experience with the IELTS reading test. I can say that this experience was great and useful as it was an opportunity for us to have an idea about how the test looks like. However, the test was very difficult where they were three different reading tests and each one of them was too challenging (S1). Moreover, I faced difficulty regarding my time even though there was a specific time for each passage. I faced some challenges during the reading of the text itself. First, there were a lot of lexical items and words that I did not understand their meaning directly because mostly there were technical words. Second, the reading passages were long and at the same time they were difficult and that cost a lot of time to finish reading and then moving to answer the questions."

In a similar vein, another student said:

"The first difficulty which I faced with the IELTS Academic Reading test was time management. I had no plan on how I would answer the entire questions effectively and on time. Starting from reading passage one, I faced my second difficulty - the new lexical items which were challenging to me. It was difficult to understand the meaning of 'escapement', 'the pendulum', etc. The second passage was full of acronyms such as FAA, ATC, IFR, and VFR which were difficult for me to know what they stand for. When I reached the third passage, I was left with ten minutes only. The main problem was matching paragraphs with statements question had many distractors. As a result, I was a bit confused."

A third student stated:

"There were some challenges that I faced when I did the test. First, I find it difficult to manage the time to answer all the questions in a specific time. Second, there were some new topics and information which I did not cover before. For example, the last reading passage includes "Issues Affecting the South Resident Orcas" - was new and had a lot of unfamiliar knowledge that confused me. Third, some paragraphs had many new and difficult vocabularies and items such as 'Coho', 'Chinook', 'polychlorinated', 'kayakers', 'kayak' and others. Some questions required summarising ideas in more than three words and this was difficult.

A fourth student wrote:

"When I saw the number of questions and the length of the passages and paragraphs, I felt scared and nervous. I was thinking about how should I manage the time and give each part of the test the appropriate time. When I started answering the questions, I tried hard to finish the test within one hour. Unfortunately, I faced difficulty in managing the time, I was struggling with the gapsfillings tasks and I spent almost half an hour in the first passage. I was anxious because I was still left with two passages which were more difficult than the first two passages. I lost most of my time because I was trying to understand the meaning of every single word and sentence as I was scanning the whole paragraph."

These participants pointed to a shared lack of adequate time-management skills. At the same time, despite their being in an English teaching undergraduate programme and having taken advanced reading courses, they still encountered difficulties with figuring out the meaning of unknown and technical vocabulary, including acronyms. Their accounts suggest that these students lacked critical reading skills, among which is being able to use non-textual clues to deduce the meaning of unknown lexical items, such as acronyms and affixes. 
The above-mentioned students' experience of the reading component of the Academic IELTS test has been shared by other studies, especially the problems with time management (Al-Issa, Al-Bulushi, \& Al-Zadjali, 2016). The extracts show that having good time-management skills is essential for a good score or band in the IELTS test. Additionally, the students' accounts demonstrate that subsidiary reading skills are equally important, such as deducing the meaning of unknown words. Also, as predictable, lack of schematic knowledge about the topics seriously impaired their comprehension of the reading passages. At this point, the cultural dimension of IELTS training takes on importance. All reading passages in the Academic IELTS tests are or represent authentic materials taken from books, journals or newspapers and deal with affairs and topics which are often commonplace in the West. It is, therefore, important to fill the gaps in the knowledge base of test-takers whose home cultures do not afford a central role to reading texts beyond those that appear on social networking sites, watching informative programmes such as documentaries, and listening to current affairs podcasts. It may not be forgotten that the linguistic layer of reading comprehension is in and of itself challenging even when the readers share the same schemata of the writers, so how much more so when the writer and the readers do not share a common conceptual ground?

Another student reported his experience as follows:

"I was not familiar with the test rubrics, so it took me minutes to go and check each question with full comprehension. The second passage was more difficult than the first. I spent most of the exam time in this passage. Unfortunately, the time was over without covering the last passage. The lexical items were somehow difficult i.e., 'aggressive', 'solidify', 'lingcod', 'tremendous', 'cetaceans' and 'spewed'. The lack of familiarity with the topics was an issue."

This excerpt adds two more elements to the previous two (i.e. lack of adequate time management and vocabulary processing skills): lack of familiarity with the rubrics and low reading speed. These difficulties were also faced by other students, such as the following.

"I faced a real problem in answering the true/false/not given questions properly because of time management. I spent most of the time reading the texts while I only needed to scan the important parts or paragraphs. Second, I had no experience or enough knowledge about IELTS. I spent half an hour on the first passage reading it slowly and answering the questions which I answered all of them correct - while it is the easiest one. The third passage was a mess to me, I had only ten minutes or less to answer the questions and I almost felt lost. The worst thing was the test anxiety and pressure that I felt it."

Consequently, if the students had prepared themselves properly by becoming thoroughly acquainted with the format of the test (e.g. answering the true/false and given/not given questions), they would have had fewer problems with time management.

Also, although the participants had been taught how to skim and scan texts (in the English foundation courses and at least two other advanced reading courses), that was not enough because they lacked some of the conceptual background knowledge. Reading is not only a question of having practical skills; it also implies having the prerequisite knowledge base. The following excerpts interestingly reinforce this idea.

One student reported:

"The challenges that I faced while I was answering the reading test are: first, the passages included new vocabularies, as a result, I did not understand some of the sentences which I read them more than three times, but I did not understand them. Second, I did manage my time well as I spent most of my time answering passage three. Third, matching headings to paragraphs were difficult. Fourth, some questions require limited numbers of words, for example (no more than three words), so I tried to minimise the words to respond to the instructions which were 
another difficult task. Fifth, sometimes the answer is indirect, for example, and they give the synonyms of words in questions instead of the actual words in the paragraph so I found it difficult to understand such words."

Another student went on to say:

"On one side, there were several challenges that I faced when I was doing the IELTS reading section. One of these challenges was that I was not familiar with topics and I have not come across such topics. Moreover, there were many new vocabularies that I did not know their meanings. Also, the structures of some of the sentences were somehow difficult to be understood. Regarding the questions, I faced difficulties to get the answers from the texts because some answers were not obvious. In other words, the answers were not direct so they required deeper reading. Therefore, there were a lot of troubles that I found while I was doing the IELTS reading section.

The second excerpt cited above mentions another type of difficulty: lack of advanced knowledge of grammar. This was also remarkable because these students had had various grammar courses in the General Foundation Program and two advanced grammar courses in the B.Ed. in the English language. This situation suggests that IELTS trainers must not blindly accept the learners' "formal" language learning track record as a reflection of their knowledge and skills without testing it in the practice.

Finally, the following excerpt indicates that some of the participants experienced test anxiety, and this made it more difficult for them to perform well.

"I was full of negative thoughts at the beginning when I first saw the number of reading texts and how long the reading passages are and their density. Furthermore, my worries started about how I would manage my time to finish all the readings in the specified time because if I started to read everything, I would end up without answering all the questions. It was full of advanced complex vocabulary and words which I couldn't even guess their meanings from the text. The acronyms also were a huge challenge for me."

In short, the participants indicated that they experienced difficulties with the following elements involved in the reading component of the Academic IELTS test: (1) time management, (2) vocabulary strategies, (3) schematic knowledge of the topics, (4) required reading speed, (5) familiarity with the test format and rubrics, (6) advanced knowledge of grammar, and (7) test anxiety.

\subsection{The accommodation strategies}

The issue of coping strategies appeared as a recurrent theme in the data analysis. Some of these strategies appeared to be more effective and widely used than others. The findings show that the participants developed their own largely intuitive/informal coping mechanisms to help them handle the reading component of the Academic IELTS test. For example, they frequently resorted to guessing, topdown processing, skimming and scanning, and matching words in the questions and the passages; at the metacognitive level, they also developed their cognitive and reading comprehension strategies as academic reading usually involves informational processing far beyond the level of propositional comprehension (Chalmers \& Walkinshaw, 2014). The quotes below illustrate such accommodation strategies.

A student reported:

"To handle the IELTS Academic Reading challenges, I tried to guess the meaning of difficult words from the context. Then I started skimming the whole text to get general ideas for those questions that required spotting out certain information by using scanning strategies. In most cases, I used guessing but it didn't work well for all times. One of the effective strategies that I 
used is the top-down processing by relying on my knowledge about the topic and it was really helpful for me. Another effective strategy I used was highlighting the keywords in the questions and then locating them with the text and this also was helpful."

Another student showed that these strategies were common among the group.

"I used some techniques to reduce these reading challenges. The first techniques were to read the questions first before reading the text. This helped me to spot the answers while surveying the text. Secondly, I made skimming and scanning to answer the questions especially in reading passage one question.

The latter went on to list two other strategies: using illustrations as a clue and prioritizing some questions over others.

"I also used the given picture of the 1670 lever-based device to identify the meaning of difficult words and I succeeded in getting some of them correct. I also left the difficult questions and I moved the easiest ones to save time."

The use of non-textual information, such as pictures, was a prominent strategy used by students to work out the meaning of new words and comprehend the passages in a better way.

Another student employed the highlight-read-search strategy, whereby they mapped the information in the paragraphs as a way of sketching the conceptual structure of the passage. Identifying the keywords, deducing meaning from the context, and activating the pertinent schemata were other strategies that helped the student comprehend and use what their highlight-read-search procedure had helped them select.

"I tried to handle those challenges by following some strategies. I used to highlight, read and search strategy. When I started to answer any reading passage, first I highlighted the main idea of each paragraph from the first sentence. Second, I read the question and determined the keywords in each question. Then I searched for the answer after I knew the relationship between the keywords and the highlighted idea. This strategy was useful because it helped me to save my time. Moving to new words and vocabularies challenges, I tried to understand the meaning of new words by guessing and using some contextual clues and the words that I couldn't guess, I skipped them easily. For uncommon topics for me, I tried to evoke my poor background knowledge in this area."

Some students, such as the one speaking below, used several of the above-mentioned strategies. In their case, they read the instructions and questions before they embarked on the reading. This reveals the students' comprehension of the fact that the IELTS tests are not for learning but for measuring performance, or task achievement.

"I started reading the instructions and the questions before reading the passages. I underlined the keywords in the text and then I moved to answer the questions. I also kept the difficult questions to answer them to the very end of the exam to save time. I always find this strategy as the most effective technique in reading tests. However, I sometimes need to scan the text before reading the questions to get a general idea, and then I read the questions."

This student's testimony suggests that reading strategies such as scanning and skimming should be given their due place in the reading courses to help students to read more purposefully.

Another student used several of the above-mentioned strategies but also added a new one: time management.

"Before starting the test, I divided up my time which is 60 minutes among the three passages. I allocated 15 minutes for the first passage, 20 minutes for the second passage, and 25 minutes 
for the last passage. This strategy was really helpful as it enabled me to answer all the questions. The second strategy that I employed, was underlining the keywords in the questions and I looked for them in the reading texts. This strategy worked well for me. The third strategy I used was inference and scanning for specific information in answering the true/false/not given tasks. These strategies were used successfully. Finally, I tried to make use of non-textual information such as pictures and illustrations and they were of great help to me."

By dividing up the total time by the number of passages, the above student made sure that they stayed on course. Notably, this strategy helped them avoid falling prey to anxiety or stress.

\section{Discussion}

This study is significant as it reported on the experiences of 45 Omani English-major students as they sat for the reading section of a mock Academic IELTS test. To the best of our knowledge, this was the first study of its kind to investigate the challenges and accommodation strategies of Omani students in the Academic reading component of the Academic IETLS test.

The findings of the current study revealed that Omani English-major students tend to experience a range of challenges relating to the reading component of the Academic IELTS test. The main difficulties had to do with time management, using appropriate reading strategies, working out the meaning of lexical items from the context, and the lack of background knowledge about the exam topics and genres. These findings seem to be consistent with other findings in the literature (e.g., Ahmadian, Poulaki, \& Farahani, 2016; Alghail \& Mahfoodh, 2016; Chalmers \& Ian Walkinshaw, 2014; Chowdhury, 2018; Feng \& Chen, 2016; Guntur \& Pordanjani, 2019).

Additionally, the study findings show that students employed certain strategies to help them deal with reading comprehension difficulties. The academic reading strategies reported in this study are consistent with various other studies (e.g., Ahmadian, Poulaki, \& Farahani, Alshammari, Al-Issa, AlBulushi, \& Al-Zadjali; 2016, Chalmers \& Walkinshaw, 2014; Chowdhury, 2018; Feng \& Chen, 2016; Wahyono, 2019) in that at the metacognitive level, students employed certain strategies which helped them to minimize some of the reading comprehension challenges during the test. This is because challenges in the IELTS Academic Reading test, as these cited studies suggested, can arise from several causes, such as lack of practice, poor time-management skills, poor critical reading skills, lack of shared knowledge between the reader and the text writer, lack of familiarity with the topic, lack of background knowledge, low language proficiency, lack of adequate vocabulary, and lack of proper reading and learning strategies. The literature has various examples of studies on EFL/ESL students' difficulties in the reading component of the IELTS test.

The findings also showed that the participating students used several accommodation strategies to handle their reading test problems. These coping strategies range from cognitive to metacognitive strategies, namely guessing, highlighting and underlining key ideas, skipping, predicting, using linguistic clues to work out the meaning of words, re-reading, using non-textual clues, etc.

Although this study has achieved its aims, some inevitable limitations merit consideration. The study was conducted on only 45 students, and the findings cannot be taken as representative of the experiences of all Omani students with the reading component of the Academic IELTS test. The results of this investigation may not be an accurate representation of the experiences of the other cohorts of Omani English-major students or in other similar contexts. Another limitation of the study was that it focuses on students' reflections and experiences of only the reading component of the test. There is a need for other studies considering the remaining skills so that complementary insights may be gained. 
Due to the small nature of the study, the reported findings are not intended for generalisation, but we believe that the implications and recommendations based on these findings are illuminating and insightful if taken and adopted by IELTS practitioners in other similar educational contexts globally. Despite these potential limitations, the researchers are confident that all the collected data were appropriate for the research questions and have provided insights and pedagogical implications for IELTS practitioners and researchers.

\section{Conclusion}

In conclusion, the participants' reflections have demonstrated that they encountered a range of difficulties during the reading component of the Academic IELTS test. However, the most recurring challenges are managing time during the reading test and answering all questions within the specified time. There was general agreement among the participants that unknown lexical items were a noticeable challenge for them during the IELTS Academic Reading test. This happened mostly as a result of their lack of familiarity and background knowledge with the exam topics which hampered their comprehension of the texts. Interestingly, the findings suggest that majoring in English language and studying through the medium of English for several years does not guarantee that one would necessarily obtain a high IELTS score band. Overall, despite the challenges they faced, the participants considered taking the IELTS Academic Reading mock test under exam conditions a golden opportunity for them to become more familiar with the test formats and instructions. The challenges seem to be the result of discrepancies between what they studied in their literacy-oriented courses on their degree programme and the demands of the IELTS test, particularly Academic Reading. The findings reveal that time pressure, unfamiliar vocabulary and demands on working memory appeared to negatively impact participants' performance on the test in question. Evidence from findings suggests that regardless of having a good IELTS score preparation courses are of great value, especially for those students with a low GPA in order to enhance their learning experiences and to prepare them for a new work environment and sociocultural context.

In light of the study findings, the following recommendations and implications can be made:

First, the reading component of the IELTS test requires special attention in IELTS preparatory courses. Teachers should allocate more time to raising students' awareness about the nature, structure, and types of questions used in the IELTS test in general and its reading component in particular.

Second, since IELTS is all about test-taking techniques and strategies, more practice is required on these techniques and strategies. Teachers should also build on students' prior strategies and techniques and further enhance them with more practice. Teachers of IELTS preparatory courses should draw on IELTS research findings, particularly those on the reading component, and should discuss them with the students to further raise their awareness and develop their test-taking strategies and techniques.

Third, students should be exposed to a wide range of text types and genres. The texts should be analysed for their overall rhetorical and organizational structure as well as the knowledge, the linguistic features, and the knowledge base that they presuppose.

Fourth, IELTS-oriented courses should be introduced very early in the curriculum and should be taught until the graduation year. A parallel IELTS preparatory course should also go side by side with these degree courses.

Fifth, students should be engaged in more IELTS research projects so that they become aware and familiar with the different aspects of the test. Intensive practice on reading skills and strategies should be introduced. A comparison between the General and Academic IELTS tests should be made 
particularly with regards to the reading comments in both tests so that students understand and appreciate the content and scope of the reading requirements in both types of IELTS test.

Sixth, assessed mock IELTS exams, under exam conditions, should be conducted regularly so that students can learn to reduce test anxiety by familiarizing themselves with the test.

Finally, speed-reading and critical courses should be integrated into the degree programmes to help students develop their critical and fast reading skills. Higher education institutions should establish a reading culture that has potential personal, social, and economic benefits for the graduates (Al Mahrooqi \& Denman, 2016).

To sum up, despite the challenges and controversies presented by IELTS to the graduates and wider community, the IELTS test still seems to be a powerful gatekeeping tool for screening English language teaching graduates based on their language proficiency before they enter the job market.

\section{Ethics Committee Approval}

The author(s) confirm(s) that the study does not need ethics committee approval according to the research integrity rules in their country (Date of Confirmation: September 12, 2020)

\section{References}

Ahmadian, M., Poulaki, S. \& Farahani, E. (2016). Reading strategies used by high scoring and low scoring IELTS candidates: A think-aloud study. Theory and Practice in Language Studies, 6(2), 408-4016.Doi: 10.1570ltpls.0602.25

Alderson, J.C. (2000). Assessing reading. Cambridge, UK: Cambridge University Press. Doi: 10.1017/ cbo9780511732935

Alghail, A.A.A. (2016). Academic reading difficulties encountered by international graduate students in a Malaysian university. Issues in Educational Research, 26(3), 369-386.

Al-Issa, A., Al-Bulushi, A., \& Al-Zadjali, R. (2017). Perceptions of the selection criteria of Omani English language teachers: Implications for policy reconsideration. Journal of Language and Linguistic Studies, 13(2), 235-259.

Al-Issa, A., Al-Bulushi, A.H., \& Al-Zadjali, R. (2016). Arab English Language Teaching Candidates Climbing the IELTS Mountain: A Qualitatively Driven Hermeneutic Phenomenology Study. The Qualitative Report, 21(5), 848-863.

Al-Issa, A. (2020). The language planning situation in the Sultanate of Oman, Current Issues in Language Planning, 1-68. Doi: 10.1080/14664208.2020.1764729

Al-Mahrooqi, R., \& Denman, C. (2016). Establishing a Reading Culture in Arabic and English in Oman. Arab World English Journal (AWEJ), 7(1), 5-17.

Alshammari, M.M. (2016). IELTS Academic Reading module test: Validity and Reliability. British Journal of English Linguistics, 4(2), 26-37.

Cambridge English IELTS 8. (2011). Cambridge English IELTS 8: Authentic examination papers from Cambridge ESOL. Cambridge: Cambridge University Press.

Chalmers, J., \& Walkinshaw, I. (2014). Reading strategies in IELTS tests: Prevalence and impact on outcomes. English Australia Journal, 30(1)24-39. 
Charge, N., \& Taylor, L.B. (1997). Recent developments in IELTS. ELT Journal, 51(4), 374-380.

Chowdhury, S. (2009). Gaining proficiency in the reading module in IELTS: A study on the efforts of Bangladeshi students. The Dhaka University Journal of Linguistics, 2(3), 125-140.

Çiftlikli, S. (2018). The relationship between perceptual learning styles and language learners' success in reading tests. folklor/edebiyat, 4,173-190. Doi: 10.22559/folklor.310

Feng, Q., \& Chen, L. (2016). A study on teaching methods of reading comprehension strategies by comparison between TEM-4 reading comprehension and IELTS Academic Reading comprehension. Journal of Language Teaching and Research, 7(6), 1174-1180. Doi:10.175507/jltr.0706.15

Grabe, W. (2009). Reading in the second language: Moving from theory to practice. Reading in a Foreign Language, 22(2), 339-342.

Green, A. (2019). Restoring the perspective on the IELTS test. ELT Journal, 73(2), 207-2015.

Green, A. (2007). Washback to learning outcomes: a comparative study of IELTS preparation and university pre-sessional language courses. Assessment in Education, 14(1), 75-97. Doi: $10.1080 / 09695940701272880.1$

Guntur, L.M.F., \& Pordanjani, S.R. (2019). Exploring the challenges of reading comprehension teaching for English proficiency test preparation class in Indonesia. ESL Journal on Interdisciplinary Studies on Humanities, 2(3), 321-330.

Hashemi, A., \& Daneshfar, S. (2018). A review of the IELTS test: Focus on validity, reliability, and washback. IJELTAL (Indonesian Journal of English Language Teaching and Applied Linguistics), 3(1), 39-52.

Hellekjær, G.O. (2009). Academic English reading proficiency at the university level: A Norwegian case study. Reading in a Foreign Language Journal, 21(2), 198-222.

Hughes, A. (2003). Testing for language teachers. Cambridge: Cambridge University Press.

IELTS Handbook. (2007). Prepare for IELTS skills and strategies: Book two; Reading and Writing. The University of Cambridge, ESOL Examinations: Cambridge University Press.

Issitt, S. (2008). Improving scores on the IELTS speaking test. ELT Journal, 62(2), 131-138. Doi: $10.1093 / \mathrm{elt} / \mathrm{ccl} 055$

Kendeou, P.M., Krista, R., \& Fulton, S. (2011). Reader and text factors in reading comprehension processes. Journal of Research in Reading, 34(4), 365-383. Doi.org/10.1111/j.14679817.2010.01436.x

Koda, K. (2007). Reading and language learning: Cross-linguistic constraints on second language reading development. Language Learning, 57(1), 1-44.

Kovalenko, M. (2018). The validation process in the IELTS reading component: Reading requirements for preparing international students. Journal of Language and Education, 4(1), 63-87. Doi: 10.17323/2411-7390-2018-4-1-63-78

Li, Y. (2018). A comparison of TOEFL iBT and IELTS reading tests. Open Journal of Social Sciences, 6, 283-309. Doi: 10.4236/jss.2018.68023

Lougheed, L. (2016). Barron's IELTS the leader in test preparation. USA: Barron's Educational Series: 
Marzban, A., \& Barati, Z. (2016). On the relation between critical thinking, languages learning strategies, and reading comprehension of male and female intermediate EFL university students. Theory and Practice in Language Studies, 6(6), 1241-1247. Doi:1016/j/tpls.0606.14.

Meneghetti, C., Carretti, B., \& De Beni, R. (2006). Components of reading comprehension and scholastic achievement.Learning and Individual Differences Journal, 16(4), 291-301. Doi: 10.1016/j.lindif.2006.11.001

Mirzaei, A., Vincheh, H.M., \& Hashemian, M. (2020). Retrofitting the IELTS reading section with a general cognitive diagnostic model in an Iranian EAP context. Studies in Educational Evaluation, 64, 1-10. Doi:org/10.1016/j.stuedu.2019.100817

Pearson, W.S. (2019). Critical perspectives on the IELTS test. ELT Journal, 73(2), 197-206.

Phakiti, A., \& Li, L. (2011). General academic difficulties and reading and writing difficulties among Asian ESL Postgraduate Students in TESOL at an Australian University. RELC Journal 42(3) 227 -264. Doi: 10.1177/0033688211421417

Schoepp, K., \& Garinger, D. (2016). IELTS and academic success in higher education: A UAE perspective. International Journal of Applied Linguistics \& English Literature, 5(3), 145-151. Doi:org/10.7575/ijalel.v.5n.3p.145

Suacilli, C.I.M., Um, S.E., Velasuez, J.M., Villaflores, H.N.R., \& Ceuena, M.B. (2016). Critical reading strategies, reading comprehension and writing performance of ESL college students: A correlational study. International Journal of Advanced Research, 4(9), 610-623.Doi: 10.21474/IJAR01/1526

Templer, B. (2004). High-stakes testing at high fees: Notes and queries on the international English proficiency assessment market. Journal of Critical Educational Policy Studies, 2(1), 189-226.

Uysal, H.H. (2009). A critical review of the IELTS writing test. ELT Journal, 64(3), 114-330.

Wahyono, E. (2019). Correlation between students' cognitive reading strategies and reading comprehension. Jurnal Studi Guru dan Pembelajaran, 2(2), 256-263.Doi. org/10.30605/jsgp.2.3.2019.61

Yang, Y., \& Badger, R. (2015). How IELTS preparation courses support students: IELTS and academic socialisation. Journal of Further and Higher Education, 39(4), 438-465. Doi: 10.1080/0309877X.2014.953463

Ying, Z. (2011). IELTS preparation courses in China: The reading comprehension task. Kristianstad University, Sweden.

Zhengdong, G. (2009). IELTS preparation course and student IELTS performance: A case study in Hong Kong. Regional Language Centre Journal, 40(1), 23-41. Doi: 10.1177/0033688208101449 


\section{Ummanlı İngilizce braşındaki öğrencilerin IELTS akademik okuma sınavlarındaki Zorlukları ve tikel uyum stratejilerini ortaya çıkarmak}

\section{$\ddot{O} \mathbf{z}$}

IELTS, bir tarama bekçisi olarak kullanılır ve Ummanlı öğrencilerin iş gereksinimlerini karşılamalarında çok önemli bir rol oynar. Bu makale, Ummanlı İngiliz lisans öğrencilerinin Akademik IELTS'in okuma bölümündeki deneyimleri hakkındaki düşüncelerini rapor etmektedir. Çalışmanın temel amacı, EFL / ESL öğretmenlerini ve IELTS sınav görevlilerini ve araştırmacılarını bilgilendirmek için zorluklarını ve başa çıkma stratejilerini aydınlatmaktır. İngilizce eğitimi alan 45 Ummanlı öğrenciye sınav koşulları altında bir IELTS sahte okuma testi uygulandı ve katılımcılardan aşağıdaki sorulara yanıt olarak yansıtıcı bir makale yazmaları istendi: "IELTS Akademik Okuma Testinde karşılaşı̆ı̆ınız zorluklar nelerdi? ve bu zorluklarla nasıl başa çıktınız? " Cevaplarında, testle ilgili deneyimlerine ve zorluklarına (ör. Biliş, içerik alanı bilgisi ve test okuma türlerine aşinalık eksikliği) ve zorlukları ele alma stratejilerine değindiler. Veriler kodlanmış ve tematik olarak analiz edilmiştir. Bulgular, öğrencilerin bir dizi bilişsel ve üstbilişsel zorluklar ve çok sayıda başa çıkma stratejisi rapor ettiklerini gösterdi. $\mathrm{Bu}$ makale, öğrencilerin yanıtlarının analizi yoluyla ortaya çıkan bazı pedagojik çıkarımları ve fikirleri ortaya çıkarmaktadır.

Anahtar Sözcükler: tikel uyum stratejileri; zorluklar; deneyimler; Ummanlı İngilizce öğrencileri; IELTS Akademik Okuma testleri

\section{AUTHOR BIODATA}

Holi Ibrahim Holi Ali is an assistant professor of applied linguistics \& TESOL at the Department of English Language \& Literature in the University of Technology and Applied Sciences, Rustaq, Sultanate of Oman. He has a PhD in applied linguistics from the University of Huddersfield, UK. His teaching and research interests include English-medium instruction (EMI), standardized testing and TESOL. He has presented widely and published extensively in peer-reviewed journals.

Qasim Al Washahi is the English Assistant Program Director for the University of Technology and Applied Sciences and Rustaq College of Education, Sultanate of Oman. He specialises in differential learning and language teaching strategies as well as digital education. He coordinated the GFP at Rustaq for many years and is now actively involved in QA in HEIs and IELTS.

Awad Alhassan is an Assistant Professor of Applied Linguistics \& TESOL at the department of English Language \& Literature in Dhofar University, Sultanate of Oman. He is also affiliated to the University of Khartoum in Sudan. He has an MA \& PhD in applied linguistics from the University of Essex, UK. His teaching and research interests include TESOL, EAP, academic writing and English-medium instruction in higher education. He has presented at several international conferences and published in peer-reviewed journals. His research appeared in journals such as Language Teaching Research \& Cogent Education. 